\title{
BMJ Open A qualitative analysis of New Zealand retailers' responses to standardised packaging legislation and tobacco industry opposition
}

\author{
John Guthrie, Janet Hoek, Ella Darroch, Zoë Wood
}

To cite: Guthrie J, Hoek J, Darroch $\mathrm{E}$, et al. A qualitative analysis of New Zealand retailers' responses to standardised packaging legislation and tobacco industry opposition. BMJ Open 2015;5:e009521. doi:10.1136/bmjopen-2015009521

- Prepublication history and additional material is available. To view please visit the journal (http://dx.doi.org/ 10.1136/bmjopen-2015009521).

Received 24 July 2015 Revised 14 October 2015 Accepted 16 October 2015

CrossMark

Department of Marketing, University of Otago, Dunedin, Otago, New Zealand

Correspondence to Professor Janet Hoek; Janet.hoek@otago.ac.nz

\section{ABSTRACT}

Objectives: Many of the approximately $8000 \mathrm{New}$ Zealand retailers selling tobacco are small stores that tobacco companies have represented as victims of policy measures designed to reduce smoking. Despite this depiction, many retailers experience considerable ambivalence in selling tobacco, a product they know harms their customers. We explored how retailers perceived the proposed introduction of standardised (or 'plain') packaging and their assessment of arguments made by tobacco companies in submissions on proposed standardised packaging legislation.

Participants: Using qualitative in-depth interviews, we recruited and interviewed 23 retailers of dairies (small convenience stores), small supermarkets, and service stations.

Analyses: Data were analysed using a protocol-driven approach; this stance enabled direct analysis of tobacco companies' arguments, particularly those purporting to represent retailers' concerns.

Results: Retailers were concerned about the financial implications of standardised packaging and the effects it may have on their ability to provide rapid and efficient customer service. However, few thought standardised packaging would foster illicit trade or spawn further regulation; most placed public health goals ahead of tobacco companies' 'rights', and many supported government intervention to protect population health.

Conclusions: Retailers held ambivalent views on standardised packaging; while they were concerned about short-term effects on their business, they recognised the harm smoking causes. Policymakers and health researchers could collaborate more effectively with retailers by assisting them to create financially viable roles more compatible with public health objectives.

\section{BACKGROUND}

Tobacco manufacturers have long faced an atypical challenge: when used as intended, their products dramatically shorten users'
Strengths and limitations of this study

- Use of in-depth qualitative methods allowed detailed probing of a key stakeholder group's views on standardised packaging.

- The findings provide new insights into the need for stronger links between public health groups and stakeholder groups such as retailers; collaborations could ameliorate the perceived negative impact of tobacco control policies.

- The high proportion of participants who did not speak English as a first language made data collection more complicated. Nevertheless, careful interviewer probing ensured collection of highquality data.

lives and cause up to two-thirds to die prematurely. ${ }^{1}{ }^{2}$ In these circumstances, acquiring new customers takes on a heightened strategic importance, made more acute by the strenuous efforts many governments have undertaken to reduce smoking prevalence. ${ }^{3}$ Given marketing's role in promoting and sustaining brand and product category growth, regulators have paid particular attention to elements of the tobacco marketing mix. As a result, many nations now ban tobacco marketing and promotion, ${ }^{4}$ require tobacco products to be concealed in retail stores, ${ }^{5}$ and increase the excise tax on tobacco at regular intervals. ${ }^{6}$

Until recently, largely unregulated on-pack tobacco branding had grown in importance as other marketing media became increasingly restricted. ${ }^{7-12}$ Smoking satiates a physiological need by delivering nicotine while tobacco packaging, which features carefully designed brand livery, enables smokers to construct, maintain and project desired social identities. ${ }^{7} 11$ Fully implemented in Australia in late 2012, standardised packaging replaces attractive brand logos with aversive colours and larger warnings; tobacco 
brand names appear in a standard size and font. Standardised packaging recognises that appealing on-pack imagery attracts new smokers and reinforces existing smokers' behaviour, and transforms packs from sophisticated marketing media into strikingly unappealing accessories. ${ }^{13}$

Given their reliance on branding to attract new and reassure existing users, tobacco companies strongly resisted standardised packaging and have subsequently opposed its introduction in every jurisdiction where it has been mooted. ${ }^{14}$ For the first time in decades, tobacco companies have publically fronted mass media campaigns, ${ }^{15}$ while simultaneously using astroturfing (creation of 'grass roots' groups) and their positions on trade associations to suggest widespread and united business opposition. ${ }^{16}$

As elsewhere, tobacco companies have enlisted support for their stance from varied stakeholders and have focused on retailers, a large and diverse group with widespread community connections. Claims that standardised packaging would place significant operational and economic burdens on the many small businesses that sell tobacco products have caused considerable concern among retailers. ${ }^{17}$ Specific arguments included that standardised packaging will increase transaction times and product selection errors, generate customer frustration, heighten security risks, and foster illicit trading of tobacco. $^{18}$

Closer analysis questions each of these claims. For example, reports of lengthened transaction times after standardised packaging came into effect, ${ }^{19}$ were based on data collected in the first week of the policy's implementation, when any initial problems were most likely to be encountered, and did not appear to have allowed for a settling down period. The conclusions contrast with a postimplementation study that found while initial retrieval times increased, these reverted to prestandardised packaging times by the second week of implementation. ${ }^{20}$ Australian retailers' experiences suggest it is highly unlikely that New Zealand retailers will experience a sustained increase in transaction times.

Nor has the research evidence supported other concerns that would allegedly affect retailers. Arguments that transaction errors would increase are inconsistent with findings from a simulation study, where participants made more errors selecting branded tobacco products $(40.4 \%)$ relative to products in standardised packaging $(17.3 \%){ }^{21}{ }^{22}$ Concerns that increased transaction times and retrieval errors will cause customer frustration and result in some customers taking their business elsewhere, particularly to larger outlets, also lack robust support. ${ }^{20} 23{ }^{24}$ While retailers reportedly hold concerns about the ease of stock management and heightened security problems, these concerns are not based on objective evidence of burglaries, robberies or theft, but on speculation. ${ }^{18} 19$

Tobacco companies have also argued that standardised packaging would undermine their intellectual property
(IP) rights, put New Zealand in breach of its obligations to various World Trade Organisation Agreements, and result in expensive legal action. ${ }^{18}{ }^{23}$ However, the proposed legislation does not affect any tobacco company's rights to register, own and enforce their IP, but rather prevents use of these tools as promotional devices (an activity that arguably breaches New Zealand's Framework Convention on Tobacco Control (FCTC) obligations).

Claims that standardised packaging will set a precedent imply the policy has wide-ranging implications and may later be introduced in other product categories. British American Tobacco suggested a similar regime will be applied to alcohol, and other groups have suggested unhealthy food products may also be candidates for plain packaging. ${ }^{18}$ While the Government may take these steps in the future, any new proposals involving standardised packaging would have to proceed independently through a full legislative process, where they would withstand close scrutiny and require a majority vote to become law.

Tobacco companies have also claimed that plain packaging will encourage illicit trade ${ }^{18}$ by leading consumers to focus more on price as a differentiating attribute. A KPMG report commissioned by British American Tobacco stated that illicit smoking in Australia had increased dramatically post plain packaging implementation. ${ }^{25}$ However, this report attracted widespread criticism for using an unreliable methodology. ${ }^{26}{ }^{27}$ Furthermore, official data from the Australian National Drug Strategy Household Survey suggest the estimates are inaccurate; this survey found that illicit trade was around $2-3 \%$ of total consumption (substantially less than the KPMG estimate of $13.9 \%) .^{28} 29$

In their efforts to represent retailers' concerns, tobacco companies imply widespread opposition to standardised packaging exists. However, these claims sit uneasily alongside studies revealing retailers' ambivalence about selling tobacco and outlining their support for some tobacco marketing restrictions. ${ }^{30-33}$ This evidence suggests retailers may not share tobacco companies' perspective and could instead support public health measures.

Despite the weak support for industry claims, all countries planning to introduce standardised packaging will have to address these arguments and examine whether retailers could incur compliance costs disproportionate to the benefits that will result. ${ }^{23}$ We thus explored retailers' views on standardised packaging and examined how they construed arguments advanced by tobacco companies. Specifically, we addressed the following research questions:

$R Q 1$ : How do retailers anticipate the introduction of plain packaging and what effects do they think this policy will have on their business?

RQ2: How do retailers interpret and respond to arguments tobacco companies have used to oppose plain packaging? 


\section{METHODS}

We conducted in-depth interviews with 23 retailers from two New Zealand cities (a large and a provincial city, Wellington (WLG) and Dunedin (DUD), respectively); this approach provides opportunities to probe participants' views in detail.

\section{Sample}

As New Zealand does not have a register of tobacco retailers, we used a database compiled for an earlier study to obtain information on tobacco retailers' store name, location, type, and the New Zealand Deprivation Index score for that location. ${ }^{34}$ From this database, we drew a purposive sample stratified by store type (dairy (a small convenience store) (D), small supermarket (S) and service station (SS)) and area deprivation level. ${ }^{35}$ Potential participants were first visited in person and provided with an information sheet outlining the study purpose and their rights as participants. Interview times were then confirmed with those participants who agreed to be interviewed (15 interviews from 46 approaches in WLG; 8 interviews from 15 approaches in DUD).

Immediately prior to each interview, each participant was given a second copy of the information sheet, the interviewer explained participants' rights to them and clarified any questions they raised. Participants were assured of confidentiality and all identifying information was destroyed once the recordings had been transcribed and checked. All participants gave written consent prior to the interview initiation, including permission for the interview to be recorded. Each participant received a \$30 Warehouse voucher to recognise costs they incurred participating in the interview; this large discount store chain has a diverse product array but does not sell tobacco. Recordings were transcribed verbatim and assessed for accuracy. Table 1 summarises details of participants' store type and area deprivation.

\section{Protocol and procedure}

Our semistructured protocol explored retailers' views on selling tobacco, its importance to their business, and their perceptions of plain packaging. We also probed their responses to industry arguments outlined above, which we identified following a content analysis of

\begin{tabular}{|c|c|c|c|}
\hline Response rate & $\begin{array}{l}\text { Dairy/small } \\
\text { supermarket }\end{array}$ & $\begin{array}{l}\text { Service } \\
\text { station }\end{array}$ & Total \\
\hline $\begin{array}{l}\text { Number interviewed/ } \\
\text { number approached } \\
\text { Deprivation level }\end{array}$ & $15 / 42$ & $8 / 16$ & $23 / 58$ \\
\hline $1-3$ low & 5 & 3 & 8 \\
\hline 4-6 medium & 6 & 2 & 8 \\
\hline 7-10 high & 4 & 3 & 7 \\
\hline
\end{tabular}

submissions to government consultations on standardised packaging.

Interviews for both locations typically lasted between 20 and $40 \mathrm{~min}$, including completion of a brief questionnaire collecting demographic information and reported smoking behaviour. A copy of the interview protocol is provided as an online supplementary material file. We conducted interviews face-to-face in participants' stores, either on the shop floor (which sometimes involved customer interruptions) or in a separate office adjacent to the store. As several participants did not speak English as their first language, we summarised responses to ensure we correctly understood these before undertaking any further probing. A review was undertaken after each interview to assess whether new idea elements continued to emerge and if the protocol should be expanded. Interviewing continued until two consecutive recordings revealed no new themes, when we determined that data saturation had occurred.

\section{Data analysis}

We analysed the interview transcripts using a protocoldriven approach as our research questions explored specific arguments that our protocol addressed directly. Two members of the research team reviewed transcripts independently, using an iterative process to identify idea elements relevant to each topic introduced in the protocol. These researchers then discussed their draft interpretations, and retested these against the transcripts for coherence and validity. In reporting the findings, we use quotations to illustrate and nuance our interpretations. Respondents are identified using regional (DUD or WLG) and store-type (D; S; SS) identifiers, and a number within each region and store group.

\section{RESULTS}

We first examined participants' perception of their role as tobacco sellers before exploring their views on problems identified in tobacco industry submissions: retail service issues (eg, increased transaction times, retrieval errors, and customer frustration) and increased security concerns. We also probed more general arguments advanced by tobacco companies (illicit trade; ownership of IP, and slippery slope claims). To ensure participants had a shared understanding of standardised packaging, we showed them a mock-up plain pack or twodimensional images prior to exploring their views on standardised packaging.

\section{Retail roles and service}

Irrespective of store size, most retailers described their business as a 'convenience' store and saw rapid, efficient provision of frequently requested products as crucial to maintaining their customer base. While many participants recognised the harms tobacco caused, some rationalised these concerns by prioritising consumers' requests and the need to respond efficiently to these: 
"It's my duty to sell it. Customer [sic] ask me, so I have to sell that. I can't refuse it...it's not good for you. It's a customer service, it's my duty" (WLG S1) and "Well it's a convenience store so for me, it's providing convenience to the customer-so um, yeah, it's just part of the business" (WLG D5). Viewing fulfilment of their role's requirements-to provide convenience-as more important than their personal opinion, helped retailers justify selling tobacco. However, a small minority differentiated their commercial actions from their personal beliefs and behaviour: "Well it's part of my job to sell tobacco, so um, it doesn't really matter whether I um, like, you know...as far as I'm not...I don't have to consume it" (DUD D3).

Not all participants felt able to rationalise the gap between their personal views and commercial role: "Um, I don't particularly like the fact that young people are coming in and buying. I can understand older people because they're already addicted but when they're just turning 18 and coming in...that's really sad and, no, I'm not happy about that" (DUD D1). However, a small number acted on their personal beliefs and reported trying to support customers they knew were attempting to quit: "So if somebody comes-a smoker comes and says 'oh I-ah, you know I am not smoking' I say "well done. Very good'. You know?" (WLG D1) and "[if someone says] I need to think about quitting it' and we always you know, encourage that thought. We say of course there are so many reasons for doing that you know, you can call the smoke Quitline and this and that..." (WLG S1).

Few retailers had seriously considered delisting tobacco because of concerns they would lose customers if they did not sell it: "It's not that you simply say-no we don't sell tobacco-it kills your business" (WLG S2). Like several others, this retailer saw tobacco as a magnet that attracted customers who then purchased higher margin items: "If you...come to buy three items, say one of them is smokes...you wanted to buy bread, milk and some groceries-but I don't stock smokes-they don't stop here-they'll go somewhere else" (WLG D9). The additional sales some participants attributed to tobacco meant the difference between continuing to trade or closing their business.

Since retailers focused strongly on the financial viability of their business, they placed a high priority on efficient service and worried that standardised packaging could compromise the speed with which they served customers: "there's a lot more room for error. With the colour packaging you can identify very quickly if you've got the right...brand and sizes. Whereas with the plain packaging they all look the same-it'll take a lot more concentration and involvement in order to get it correct" (DUD SS1).To minimise errors, several suggested they could spend more time checking packs, which would extend the transaction time: "When they're all looking the same, I think I'd want to double-check... it might slow us down-the transaction level but like again it's not the end of the world" (DUD SS2).
Not all participants expected delays, however, and even those who anticipated extended transactions expected only a short (and short-lived) service delay. Nonetheless, these participants' concern that any delay could frustrate and inconvenience their customers reflects the strong commercial imperatives they felt: "It will take a bit more time... Maybe half a minute, a minute or something like that, you know?...Yes, definitely not good because in the busy time, we've got three or four customers at a time and if we take longer time, customer don't like, you know?” (WLG D1).

Aside from a possible short-term increase in transaction times, retailers' main concern was that smokers could feel unhappy about their brand's new appearance, and take out their displeasure on retail staff. When considering the expected loss of efficiency and customer unhappiness, some retailers saw themselves as victims of a government decision that they were called on to manage: "I mean you'll have a lot of people coming in and moaning at us about it-like they moan about the price rises, like it's our fault" (DUD D1).

Feelings they had to take responsibility for others' decisions were exacerbated by 'evidence' they reported hearing from tobacco company sales staff, who they saw as credible because of the support and advice sales staff provided: "They [tobacco sales staff] give us the advice that you stock like this [that is, display brands in a particular arrangement] and they change the [brand] stocking levels" (WLG D1). Past assistance from tobacco sales staff inclined retailers to believe claims that standardised packaging had proved ineffective in Australia: "I know Australia has actually done that and this, for the smokers doesn't make a difference...I talk to the reps and...all tobacco companies...Australia has been doing that for years...I don't think there is decrease" (WLG S2). Others cited anecdotal remarks made by customers as evidence that standardised packaging would not work: "Because I've spoken to Aussies as well, 'cos we get a wide range of customers in our shop-tourists and they say they have plain packaging in Australia. It does not make any difference-to this one customer that I spoke to" (WLG D5). The apparent absence of evidence documenting plain packaging's positive effects had allowed hearsay to gain credence. However, while retailers generally endorsed concerns that standardised packaging could affect the service they offered, they had much less sympathy with other arguments adduced by tobacco companies.

\section{Assessments of tobacco industry arguments}

Very few retailers had considered standardised packaging might promote illicit trade of tobacco products; even fewer had heard of a black market for tobacco or thought one likely: 'Yeah it won't make any major difference if you...import the tobacco from ah, other countries; it's not going to happen, you know, in New Zealand" (WLG D1). If a black market was to occur, retailers thought continued price increases would be 
more likely than standardised packaging to spawn illicit trade: "It would take huge increases in price and that sort of thing to make a difference. Plain packaging by itself won't make [any difference]" (DUD SS2). Retailers' consistently rejected concerns regarding illicit trade and very few thought standardised packaging would be likely to stimulate a black market in tobacco.

While tobacco companies have argued that standardised packaging deprives them of the right to use legally registered and owned trademarks, retailers were largely unsympathetic to this claim. Most supported government action to achieve public health goals, even if these actions allegedly encroached on tobacco companies' IP: "Yes-I think the Government has [the] right to look after the people" (WLG D9). Nonetheless, a small minority sympathised with tobacco companies' position: "I think it just affects the companies' rights...'cos they design the package and they design this colours and then just Government come here and just change the... all the package-to the plain package"'(DUD S2). Overall, however, participants agreed that public health goals to reduce smoking should supercede commercial considerations and arguments regarding tobacco companies' IP rights attracted little support.

Although tobacco companies claim that standardised packaging of tobacco products would lead to government intervention in other product categories and create a 'slippery slope', very few participants accepted these arguments. Most recognised the uniquely harmful nature of tobacco and acknowledged the government's role in trying to prevent those harms: "I don't think so [standardised packaging would lead to interventions in other product categories]. Because why they are doing it for the tobacco is it harms human life. That's why they want to get rid of this, you know" (WLG D1). Retailers saw tobacco as inherently different to other products: "I think tobacco is very specific. It's not like the other ones...just addictive and harmful" (WLG S2).

Even those who saw standardised packaging of tobacco as potentially applicable to other product categories thought the government would make case-by-case decisions, using evidence specific to each product category: "I think they'd treat it on a case-to-case basis...like I said - tobacco's addicting-you're gonna get people doing it all the time anyway" (WLG S3). Again, few retailers displayed any sympathy for tobacco companies' argument.

\section{DISCUSSION}

Tobacco companies and retail associations have argued that standardised packaging will bring adverse unintended consequences for small businesses, including higher business costs, more transaction errors, and heightened security risks. ${ }^{18} 212324$ Our analysis, the first to explore individual retailers' views, questions whether retailers unanimously share these concerns and suggests many play a reluctant yet complex role in the tobacco supply network. While some retailers were highly ambivalent about selling tobacco, recognised the indisputable harms smoking causes, and felt uneasy about selling tobacco to young people, most felt they had few options, given the need to ensure their business survived in a highly competitive market. Thus while they identified strongly with concerns about compliance burdens, they had much less sympathy with other arguments and most supported government intervention to reduce smoking prevalence. Few thought that standardised packaging would increase illicit trading; most rejected tobacco companies' argument that standardised packaging unjustifiably limits IP rights and believed public health goals justified limitations on branding rights, even if they felt unsure of what standardised packaging would achieve. Participants also queried 'slippery slope' arguments and few thought tobacco standardised packaging would set a dangerous precedent. Instead, most believed the government had focused on tobacco because it is unambiguously harmful and addictive, and thus differed, in their eyes, from food and alcohol.

Although interviewing continued until data saturation had occurred, study limitations include the comparatively small sample and the fact English was a second language for many participants. Some participants also relied on tobacco companies for support and advice when dealing with policy changes; these relationships did not appear to affect their willingness to disagree with industry arguments, though we cannot assess any influence that may have been present. Finally, we explored participants' perceptions of standardised packaging rather than their actual experience of this policy. Given the policy is yet to be implemented in New Zealand and we wished to assess debate over standardised packaging, we could not avoid this limitation. Nevertheless, we ensured participants had a common understanding of plain packaging by providing them with replica packs before exploring their views.

Retailers' mixed, and at times discrepant, views on standardised packaging and arguments raised by tobacco companies reflect earlier findings and highlight tensions between concerns over their immediate livelihood and their knowledge of the widespread harm tobacco causes. ${ }^{30-32} 36$ Several studies have reported strong public support for more progressive tobacco retailing controls, and found positive media coverage of retailers who voluntarily adopt measures, including delisting tobacco. ${ }^{30} 323738$ In revealing New Zealand retailers' ambivalence regarding standardised packaging, our findings strengthen calls for an increased focus on tobacco supply networks. ${ }^{37} 39$

Ensuring retailers understand rapidly changing community norms with respect to tobacco, particularly the strong public support for standardised packaging, ${ }^{40}$ may facilitate acceptance of new tobacco control policies. Since most retailers focused on the needs of customers who smoke, continued denormalisation of tobacco products, particularly if associated with consumer boycotts of non-supportive outlets, could encourage retailers to 
align more strongly with their communities than with their suppliers. ${ }^{39}$

Evidence that retailers regarded tobacco companies as helpful and supportive, particularly when assisting them to deal with policy changes, suggests policymakers could develop stronger relationships with retailers. More frequent interactions between policymakers, health promoters, and retailers could promote the benefits tobacco control measures deliver, and ensure retailers receive more balanced information than is currently the case. Better recognition by policymakers that retailers need to run a viable business could focus attention on helping retailers transition to products that offer them better margins and do not harm their customers. At present while retailers saw smoking as harmful and some reported supporting customers who wished to quit, few had reflected on how their business contributed to that harm. Even while several said they did not like to see young people smoking, none considered how tobacco companies benefit from youth addiction. These findings suggest denormalisation efforts could focus on tobacco companies as well as smoking, and prompt retailers to consider the morality of companies that manufacture such harmful products. Developing change strategies that preserve retailers' profitability yet avoid introducing new public health problems presents a considerable challenge. Some retailers have successfully delisted tobacco; ${ }^{41}$ public health workers could develop cases on these stores and use the owners as exemplars who promote their approach to others.

Increased interactions between retailers and policymakers could ameliorate the influence tobacco companies currently have, and encourage retailers to redefine the 'service' they wish to provide. Tobacco endgame goals, which aim to reduce smoking prevalence to minimal levels, require those working in the field to 'imagine things otherwise'. ${ }^{42}$ Given retailers were largely unsympathetic to more general tobacco industry arguments, our work has highlighted a crucial opportunity to foster greater understanding of and support for tobacco control policies, such as standardised packaging. Such a change would require sympathetic understanding of retailers' financial concerns, careful planning to cultivate alternative revenue streams, and supportive policy to promote an equitable transition. ${ }^{32} 39$

Yet while a collaborative approach could increase understanding of tobacco control policy and elicit greater support for new measures, it may also take time for change to occur, particularly if tobacco companies continue developing their relationships with retailers. Nonetheless, evidence that retailers do not necessarily oppose legislative measures, so long as these are introduced equitably, suggests there is merit in examining the potential benefits of collaborating more closely with retailers. ${ }^{36}$ Furthermore, greater use of industry denormalisation programmes could increase the ambivalence some retailers already feel about selling tobacco, undermine the relationships tobacco companies have developed with retailers, and increase acceptance of policy measures.

\section{CONCLUSIONS}

Knowledge of retailers' concerns regarding standardised packaging, and their views on arguments adduced by tobacco companies, suggest many are reluctant purveyors of a product they know harms their consumers. Driven by financial imperatives, retailers view tobacco companies as supportive advisors and policymakers as unaware of the implications new measures may have. However, retailers' scepticism about the wider philosophical arguments tobacco companies have used to oppose standardised packaging suggest policymakers and health promoters have an important opportunity to work alongside retailers. Greater engagement with this key stakeholder group could promote the benefits of tobacco control measures and balance the skewed information they receive from tobacco companies. More regular dialogue could also help policymakers understand retailers' concerns and ensure new measures support retailers' financial viability while ultimately encouraging them to transition away from tobacco sales.

Acknowledgements The authors wish to acknowledge the research participants whose willingness to be interviewed allowed the study to proceed. They also thank Professor Philip Gendall, who reviewed the protocol used.

Contributors JG and JH were the project leaders; and led the research design. JH obtained funding for the project; and responded to the reviewers comments. JH, ED and ZW collected the data. JH, ED and JG prepared the manuscript. All the authors have approved the submitted manuscript and agree to be responsible for the data reported.

Funding This work was supported by the New Zealand Ministry of Health, which funded ED's scholarship stipend and met costs of the data collectionUniversity of Otago reference: 12026.

\section{Competing interests None declared.}

Ethics approval Ethics approval was granted by a Delegated Authority from the University of Otago Human Ethics Committee.

Provenance and peer review Not commissioned; externally peer reviewed.

Data sharing statement No additional data are available.

Open Access This is an Open Access article distributed in accordance with the Creative Commons Attribution Non Commercial (CC BY-NC 4.0) license, which permits others to distribute, remix, adapt, build upon this work noncommercially, and license their derivative works on different terms, provided the original work is properly cited and the use is non-commercial. See: http:// creativecommons.org/licenses/by-nc/4.0/

\section{REFERENCES}

1. Doll R, Peto R, Boreham J, et al. Mortality in relation to smoking: 50 years' observations on male British doctors. BMJ 2004;328:1519.

2. Banks E, Joshy G, Weber MF, et al. Tobacco smoking and all-cause mortality in a large Australian cohort study: findings from a mature epidemic with current low smoking prevalence. BMC Med 2015;13:38

3. World Health Organization. WHO Framework Convention on Tobacco Control. Geneva, Switzerland: World Health Organization, 2011

4. World Health Organization (2013) WHO report on the global tobacco epidemic, 2013: enforcing bans on tobacco advertising, promotion and sponsorship: Executive summary. https://extranet.who.int/iris/ restricted/bitstream/10665/85381/1/WHO_NMH_PND_13.2_eng.pdf (accessed May 2014)

5. Robertson L, McGee R, Marsh L, et al. A systematic review on the impact of point-of-sale tobacco promotion on smoking. Nicotine Tob Res 2015;17:2-17. 
6. Chaloupka FJ, Yurekli A, Fong GT. Tobacco taxes as a tobacco control strategy. Tob Control 2012;21:172-80.

7. Hoek J, Gendall P, Gifford H, et al. Tobacco branding, plain packaging, pictorial warnings, and symbolic consumption. Qual Health Res 2012;22:630-9.

8. Hoek J, Wong C, Gendall P, et al. Effects of dissuasive packaging on young adult smokers. Tob Control 2011;20:183-8.

9. Wakefield M, Germain D, Durkin S. How does increasingly plainer cigarette packaging influence adult smokers' perceptions about brand image? An experimental study. Tob Control 2008;17: 416-21.

10. Germain D, Wakefield M, Durkin S. Adolescents' perceptions of cigarette brand image: does plain packaging make a difference? $J$ Adolesc Health 2010;46:385-92.

11. Gendall P, Hoek J, Edwards R, et al. A cross-sectional analysis of how young adults perceive tobacco brands: implications for FCTC signatories. BMC Public Health 2012;12:796.

12. Gendall P, Hoek J, Thomson G, et al. Young adults' interpretations of tobacco brands: implications for tobacco control. Nicotine Tob Res 2011;13:911-18.

13. Wakefield M. Welcome to cardboard country: how plain packaging could change the subjective experience of smoking. Tob Control 2011;20:321-2.

14. Liberman J. Plainly constitutional: the upholding of plain tobacco packaging by the High Court of Australia. Am J Law Med 2013;39:361-81.

15. Hoek J. Informed choice and the nanny state: learning from the tobacco industry. Public Health 2015;129:1038-45.

16. Apollonio DE, Bero LA. The creation of industry front groups: the tobacco industry and "get government off our back". Am J Public Health 2007;97:419.

17. New Zealand Association of Convenience Stores. Convenience stores slam plain tobacco packaging as costly for retailers and a waste of time. Retail News, 2014.

18. British American Tobacco (New Zealand) Limited. Submission by British American Tobacco (New Zealand) Limited opposing the Smoke-free Environments (Tobacco Plain Packaging). Amendment Bill. 2014.

19. Roy Morgan Research. Research report for Philip Morris Ltd. Impact of plain packaging on small retailers-wave 1. Melbourne: Roy Morgan Research. 2013. http://www.aacs.org.au/wp-content/ uploads/2013/03/Impact-of-Plain-Packaging-on-Small-RetailersFinal-Report.pdf (accessed Jan 2015)

20. Wakefield M, Bayly M, Scollo M. Product retrieval time in small tobacco retail outlets before and after the Australian plain packaging policy: real-world study. Tob Control 2014;23:70-6.

21. Night'n Day Foodstores. A submission to parliament's health committee on the smoke-free environments (tobacco plain packaging) amendment bill. Christchurch: Night'n Day Foodstores, 2014

22. Carter OB, Mills BW, Phan T, et al. Measuring the effect of cigarette plain packaging on transaction times and selection errors in a simulation experiment. Tob Control 2012:21:572-7.

23. New Zealand Retailers' Association. A submission to parliament's health committee on the smoke-free environments (tobacco plain packaging). Wellington: Amendment Bill, 2014.

24. New Zealand Association of Convenience Stores. A submission to parliament's health committee on the smoke-free environments (tobacco plain packaging). Cambridge: Amendment Bill, 2014.

25. KPMG LLP. Illicit tobacco in Australia: 2014 half year report. Sydney, 2014. http://www.bata.com.au/group/sites/BAT 7WYKG8.nsf/ vwPagesWebLive/DO9FC38M?opendocument\&SKN=1 (accessed March 2015).

26. Chantler SC. Standardised packaging of tobacco: report of the independent review undertaken by Sir Cyril Chantler, 2014.

27. Cancer Council Victoria. What has happened to use of illicit tobacco since the introduction of legislation to standardise the packaging of tobacco products in Australia? Questions and answers on plain packaging in Australia, 2015 Fact Sheet No. 3. Australia: Cancer Council Victoria. https://www.cancervic.org.au/downloads/plainfacts/ Facts_sheets/Facts_Sheet_no_3_Illicit_tobacco.pdf (accessed March 2015).

28. Quit Victoria and Cancer Council Victoria. Analysis of KPMG LLP report on use of illicit tobacco in Australia. Melbourne: Quit Victoria and Cancer Council Victoria, 2013/2014. https://www.cancervic.org. au/downloads/mini_sites/Plain-facts/analysis-kpmg-llp-report-illicittobacco-aust-2013.pdf (accessed March 2014).

29. Australian Institute of Health and Welfare. National drug strategy household survey detailed report: 2013. Canberra: AlHW, 2014.

30. Hoek J, Vaudrey R, Gendall P, et al. Tobacco retail displays: a comparison of industry arguments and retailers' experiences. Tob Control 2012;21:497-501.

31. Jaine R, Russell M, Edwards R, et al. New Zealand tobacco retailers' attitudes to selling tobacco, point-of-sale display bans and other tobacco control measures: a qualitative analysis. $N Z$ Med $J$ 2014;127:53-66.

32. McDaniel PA, Malone RE. "People over profits": retailers who voluntarily ended tobacco sales. PLOS ONE 2014;9:e85751.

33. Thomson G, Hoek J, Edwards R, et al. Evidence and arguments on tobacco retail displays: marketing an addictive drug to children. N Z Med J 2008;121:87-98.

34. Marsh L, Doscher C, Robertson LA. Characteristics of tobacco retailers in New Zealand. Health Place 2013;23:165-70.

35. Atkinson J, Salmond C, Crampton P. NZDep2013 Index of Deprivation. In: Department of Public Health, ed. University of Otago, 2014. http://www.otago.ac.nz/wellington/otago069936.pdf (accessed March 2014)

36. Robertson L, Marsh L, Hoek J, et al. Regulating the sale of tobacco in New Zealand: a qualitative analysis of retailers' views and implications for advocacy. Int J Drug Policy 2015;pii: S0955-3959 (15)00251-0.

37. Whyte G, Gendall P, Hoek J. Advancing the retail endgame: public perceptions of retail policy interventions. Tob Control 2014;23:160-6.

38. McDaniel PA, Offen N, Yerger VB, et al. "A breath of fresh air worth spreading": media coverage of retailer abandonment of tobacco sales. Am J Public Health 2014;104:562-9.

39. McDaniel P, Malone R. Understanding community norms surrounding tobacco sales. PLOS ONE 2014;9:e106461.

40. Hoek J, Gendall P, Maubach N, et al. Strong public support for plain packaging of tobacco products. Aust N Z J Public Health 2012;36:405-7.

41. Richardson AJ. CVS/Caremark: the costs and strategy of a tobacco-free pharmacy. Account Perspect 2015;14:71-85.

42. Malone RE. Imagining things otherwise: new endgame ideas for tobacco control. Tob Control 2010;19:349-50. 